\title{
EVALUATION OF PHYSICOCHEMICAL PROPERTIES OF GUAR GUM- ANTIOXIDANTS EMULSION COATINGS
}

\author{
JAGRUTI JANKAR ${ }^{1}$, V.N. PAWAR ${ }^{2}$, A.K. SHARMA ${ }^{3}$, A.K. SAHOO ${ }^{4} \&$ R. C. RANVEER ${ }^{5}$ \\ ${ }^{1,2}$ MIT College of Food Technology, MIT ADT University, Pune \\ ${ }^{3}$ ICAR-National Research Centre for Grapes, Manjri, Pune \\ ${ }^{4}$ Department of Food Technology, Shivaji University, Kolhapur \\ ${ }^{5}$ PGI Institute of Post-Harvest Management, Raigad
}

\begin{abstract}
Coatings and films with different functional additives for the packaging of food commodities are appealing consumers due to their remarkable benefits. In the present research, total 27 emulsions (E1-E27) were formulated using guar gum (0.25, 0.5 and $0.75 \%)$ with different antioxidants for instance garlic oil (0.125, 0.5 and1\%), $\alpha$-tocopherol (0.2, 0.4 and 0.6 $\%$ ) and basil oil (1, 2 and 3\%). The emulsions, GGOE (guar gum-garlic-oil emulsion), GBOE (guar gum-basil oil emulsion), GATE (guar gum-a-tocopherol emulsion) were analyzed for physicochemical characteristics such as density, surface tension and antioxidant activities by four different methods such as DPPH, ABTS, FRAP and CUPRAC. Lowest surface tension was offered by E1 (0.25\% guar gum $+0.125 \%$ garlic essential oil) which improvesspreadability and enhances the adhesion between solution and fruit's surface. E2 (0.25\% guar gum + 0.25\% garlic essential oil), E11 (0.25 $\%$ guar gum $+2 \%$ basil essential oil) and E19(0.25\% guar gum $+0.2 \%$ a-tocopherol $)$ showed better results for density. DPPH and ABTS assays showed highest antioxidant activities possessed by E1 and E8 (0.75\% guar gum + 0.5\% garlic essential oil) respectively. FRAP and CUPRAC assays showed maximum antioxidant activity by E27 (0.75\% guar gum + $0.6 \%$ a-tocopherol) and E24 (0.5\% guar gum $+0.6 \%$ a-tocopherol) respectively. The results suggested that the garlic oil emulsion acquired the best results followed by a-tocopherol emulsion, proved as efficient coatings in terms of physicochemical attributes.

KEYWORDS: Coating, Guar Gum, Antioxidants, Physicochemical Characteristics
\end{abstract}

Received: Jun 06, 2020; Accepted: Jun 26, 2020; Published: Aug 06, 2020; Paper Id.: IJMPERDJUN2020660

\section{INTRODUCTION}

After China, India is the second-largest producer of fruit and vegetables. However, number of different postharvest events takes place while conveying of the produce from grower to consumer. Post- harvest losses directly impacts farmers, retailers and customers who pay higher prices due to large losses in the distribution chain. The degradation in quality of these commodities during transport from growing area to consumers is quite severe (Staff, 2018). Even though India is the principal producer of fruits and vegetables, the country suffers from an extreme degree of malnutrition as it is wasting a significant portion of farm produce owing to a poor system of the cold chain and 16 per cent of fruit and vegetables being wasted every year (Sharma, 2019). After harvesting, the biochemical changes in fresh fruits and vegetables leads to loss of moisture, exposure to pathogenic attack, loss of essential bioactive compounds occurs. To reduce these losses, numbers of chemical pesticides have been used by growers on field to prevent the deterioration commencement. On the other hand, owing to chemical nature of those pesticides, they might be harmful to human, animals and also become costly for farmers leads to their economic 
loss. To compensate these issues, there is need of active packaging of these fresh commodities which should be convenient, bio-based, compatible and nonhazardous to living beings. Edible films and coatings are already in demand to fulfill the said requirements, attracting the growers and spreading awareness in society. Fresh fruits and vegetables are going through the packaging systems using biodegradable films and edible coatings which offer unbelievable benefits. Moreover, the emulsions can be reinforced with various additives such as antimicrobials, antioxidants, and many more functional ingredients to form composite films and coatings. To make the efficient coating emulsions, physicochemical analysis of the solution has the greater importance to fulfill the desired requirements. Therefore, current research was especially emphasis on the characterization of coating emulsions in terms of physicochemical analysis.

\section{MATERIALS AND METHODS}

Different antioxidant such as Garlic oil (0.125, 0.5 and 1\%), $\alpha$-tocopherol (0.2, 0.4 and $0.6 \%)$ and Basil oil (1, 2 and 3\%) with different guar gum concentrations $(0.25,0.5$ and $0.75 \%)$ were prepared. Each solution was added with $0.4 \%$ glycerol which acts as plasticizer. Total 27 emulsions were analyzed for various physicochemical properties. All chemicals and reagents used in this study were of analytical grade.

Table 1: Composition of Guar Gum-Antioxidant Emulsions

\begin{tabular}{|c|c|c|c|c|c|c|}
\hline \multirow{2}{*}{ Guar gum (\%) } & \multicolumn{7}{|c|}{ Antioxidants Emulsions } \\
\cline { 2 - 7 } & Garlic Oil (\%) & Emulsion & Basil Oil (\%) & Emulsion & o-tocopherol (\%) & Emulsion \\
\hline 0.25 & 0.125 & E1 & 1 & E10 & 0.2 & E19 \\
\hline 0.25 & 0.5 & E2 & 2 & E11 & 0.4 & E20 \\
\hline 0.25 & 1 & E3 & 3 & E12 & 0.6 & E21 \\
\hline 0.5 & 0.125 & E4 & 1 & E13 & 0.2 & E22 \\
\hline 0.5 & 0.5 & E5 & 2 & E14 & 0.4 & E23 \\
\hline 0.5 & 1 & E6 & 3 & E15 & 0.6 & E24 \\
\hline 0.75 & 0.125 & E7 & 1 & E16 & 0.2 & E25 \\
\hline 0.75 & 0.5 & E8 & 2 & E17 & 0.4 & E26 \\
\hline 0.75 & 1 & E9 & 3 & E18 & 0.6 & E27 \\
\hline
\end{tabular}

Total 27 emulsions were formulated using guar gum and antioxidants, each at different concentration (Table 1). After glycerol addition, they stirred on magnetic stirrer and subjected to analysis of various physicochemical properties.

\section{Physicochemical Properties of Emulsions}

\section{Density}

Density is defined as the mass per unit volume, expressed in $\mathrm{g} / \mathrm{ml}$. By observing the mass of liquid divided by its volume, the density of fluid (Emulsion) was calculated.

\section{Surface Tension}

Surface tension of liquids was analyzed by using Du Nouy Ring Tensiometer following the procedure given by Khanna et al., (2017). The Du Nouy ring method is the technique by which the surface of liquids can be measured. This technique was developed by French Physicist Pierre Lecomte du Nouy in 1925. It is one of the oldest four common methods available for determining the surface tension. In the Du Nouy ring method a platinum ring is used to measure surface tension. The ring is dipped completely into the liquid to be analyzed. It is then slowly withdrawn from the liquid until maximum force is attained and the reading can be noted from the Dial and Vernear, it is a circular dial consisting of a scale 
from 0 -90 which coin-side with a vernier. The point coin-sides with the dial give the measurement of surface tension in Dynes $/ \mathrm{cm}$.

\title{
Antioxidant Activity
}

Four different methods such as DPPH (2,2-diphenyl-1-picryl-hydrazyl ), ABTS(2,2'-Azino-bis(3-ethyl-benzothiazoline-6sulfonic acid), FRAP (Ferric ion reducing antioxidant power) and CUPRAC (Cupric Reducing Antioxidant Capacity)to accurately assess the antioxidant activities of emulsions, four distinct antioxidant activity measurements were performed.

\section{DPPH Assay}

The DPPH assay of the essential oil was carried out as previously described (Okoh et al., 2011). A solution of $0.135 \mathrm{Mm}$ DPPH in methanol was prepared and $1.0 \mathrm{~mL}$ of this solution was mixed with $1.0 \mathrm{~mL}$ of the emulsion The reaction mixture was vortexed thoroughly, left in the dark at $25{ }^{\circ} \mathrm{C}$ for $30 \mathrm{~min}$ and measured at $517 \mathrm{~nm}$. The ability of the essential oil to scavenge DPPH radical was calculated as \% inhibition by the following equation:

$$
\begin{aligned}
& \% \text { inhibition }=(\text { Abs control }- \text { Abs sample }) \\
& (\text { Abs control }) \times 100
\end{aligned}
$$

Where Abs control is the absorbance of the DPPH radical + methanol; Abs sample is the absorbance of DPPH radical + Emulsion.

\begin{abstract}
ABTS Assay
The ABTS free radical assay given by Witayapan et al., (2007) was used. The pre-formed radical mono cation of ABTS was generated by oxidation of ABTS solution $(7 \mathrm{mM})$ with $2.45 \mathrm{mM}$ potassium persulfate solution in equal amount. The mixture was allowed to react for $12 \mathrm{~h}$ in the dark at $25^{\circ} \mathrm{C} .1 \mathrm{~mL}$ of the resulting solution was diluted in $60 \mathrm{~mL}$ of methanol to obtain an absorbance of $0.706 \pm 0.001$ at $734 \mathrm{~nm} .1 \mathrm{~mL}$ of the ABTS radical cation solution was added to emulsions and absorbance measured at $734 \mathrm{~nm}$. The percentage inhibition of ABTS radical by the oils was calculated using the equation described in the DPPH assay.
\end{abstract}

\section{FRAP}

This method is based on the ability of the sample to reduce $\mathrm{Fe}^{3+}$ to $\mathrm{Fe}^{3+}$ ions. At low pH, in the presence of TPTZ (Sigma Aldrich, India), ferric-tripyridyltriazine ( $\mathrm{Fe}^{3+} \mathrm{TPTZ}$ ) complex is reduced to the ferrous ( $\mathrm{Fe}^{2+}$-TPTZ) form with the formation of an intense blue colour having an absorption maximum at 593nm. The method described by Benzie and strain (1996) was followed. $2.3 \mathrm{~mL}$ of the FRAP reagent was mixed with $0.7 \mathrm{~mL}$ of the emulsion. The mixture was then incubated at $37^{\circ} \mathrm{C}$ for $30 \mathrm{~min}$ in the dark. The absorbance was measured at $593 \mathrm{~nm}$ against a blank having all the reagents excluding the sample using spectrophotometer. Increased absorbance of the reaction mixture indicates an increase of reduction capability. Trolox (Merck, India) was used as the standard. Standard curve of Trolox solution was prepared using the similar procedure from which the regression formula was derived. Results were expressed in $\mu \mathrm{g}$ of Trolox equivalents $/ \mathrm{ml}$ of extract.

\section{CUPRAC}

Cupric ion reducing capacity was measured in accordance to the method of Apak et al., (2004). $1 \mathrm{ml} 10 \mathrm{mM}$ cupric chloride, $1 \mathrm{ml} 7.5 \mathrm{mMneocuproine}$ and $1 \mathrm{ml} 1 \mathrm{M}$ ammonium acetate buffer of $\mathrm{pH} 7$ solutions were added to test tubes 
containing $2 \mathrm{ml}$ of distilled water. Emulsions were added to each test tube separately. These mixtures were incubated for half an hour at room temperature and measured against blank at $450 \mathrm{~nm}$. Trolox was used as positive reference standard. Results were expressed in mMol/ml_trolox equivalent.

\section{RESULTS AND DISCUSSIONS}

\section{Surface Tension}

Table 2: Surface Tension of Emulsions

\begin{tabular}{|c|c|c|c|c|c|}
\hline GGOE & Dyne/cm & GGOE & Dyne/cm & GATE & Dyne/cm \\
\hline E1 & $46.63 \mathrm{~h}$ & E10 & $46.13 \mathrm{f}$ & E19 & $54.20 \mathrm{i}$ \\
\hline E2 & $47.70 \mathrm{e}$ & E11 & $49.20 \mathrm{e}$ & E20 & $56.40 \mathrm{e}$ \\
\hline E3 & $48.90 \mathrm{~g}$ & E12 & $46.20 \mathrm{~g}$ & E21 & $57.10 \mathrm{c}$ \\
\hline E4 & $49.30 \mathrm{~d}$ & E13 & $51.13 \mathrm{c}$ & E22 & $54.30 \mathrm{~h}$ \\
\hline E5 & $47.33 \mathrm{f}$ & E14 & $50.43 \mathrm{~d}$ & E23 & $56.76 \mathrm{~d}$ \\
\hline E6 & $47.60 \mathrm{e}$ & E15 & $52.60 \mathrm{~b}$ & E24 & $57.33 \mathrm{~b}$ \\
\hline E7 & $51.66 \mathrm{a}$ & E16 & $53.46 \mathrm{a}$ & E25 & $55.63 \mathrm{~g}$ \\
\hline E8 & $52.33 \mathrm{~b}$ & E17 & $53.50 \mathrm{a}$ & E26 & $55.70 \mathrm{f}$ \\
\hline E9 & $52.43 \mathrm{c}$ & E18 & $50.43 \mathrm{~d}$ & E27 & $63.53 \mathrm{a}$ \\
\hline L.S.D. & 0.0738 & L.S.D. & 0.0934 & L.S.D. & 0.066 \\
\hline
\end{tabular}

The table 2 depicts the values of surface tension of emulsions in Dyne/ $\mathrm{cm}$. In case of all the emulsions, as the concentration of oil increased, level of surface tension also increased. These results were in accordance with Homayoonfal et al., (2014) who revealed that an increase in oil concentration increases the values of surface tension. The emulsions E1 $(0.25 \%$ guar gum $+0.125 \%$ garlic essential oil) has shown the least value of surface tension which is 46.63 Dynes $/ \mathrm{cm}$ followed by E10 ( $0.25 \%$ guar gum $+1 \%$ basil essential oil $)$ and E19 ( $0.25 \%$ guar gum $+0.2 \% \alpha$-tocopherol $)$ with the values of 46.13 Dynes/cm and 54.20 Dynes/cm respectively. These emulsions could offer improved wet ability and thus more efficient coating. It has been previously mentioned that the reduced values of surface tension improve the wet ability of the solution (Choi et al., 2002 and Ribeiro et al., 2007).In addition, it was also revealed as decreased surface tension of the liquid leads to improved spread ability and enhances the adhesion between solution and fruits surface (Moncayo et al.,2013).

\section{Density}

Table 3: Density of Emulsions

\begin{tabular}{|c|c|c|c|c|c|}
\hline GGOE & $\mathbf{g} / \mathbf{m l}$ & GBOE & $\mathbf{g} / \mathbf{m l}$ & GATE & $\mathbf{g} / \mathbf{m l}$ \\
\hline E1 & $0.99 \mathrm{~d}$ & E10 & $0.99 \mathrm{~d}$ & E19 & $0.99 \mathrm{~d}$ \\
\hline E2 & $0.97 \mathrm{f}$ & E11 & $0.97 \mathrm{c}$ & E20 & $0.99 \mathrm{~d}$ \\
\hline E3 & $0.95 \mathrm{e}$ & E12 & $0.97 \mathrm{c}$ & E21 & $0.99 \mathrm{~d}$ \\
\hline E4 & $1.02 \mathrm{c}$ & E13 & $0.99 \mathrm{~d}$ & E22 & $0.99 \mathrm{~d}$ \\
\hline E5 & $1.00 \mathrm{~b}$ & E14 & $0.97 \mathrm{c}$ & E23 & $0.99 \mathrm{~d}$ \\
\hline E6 & $1.00 \mathrm{a}$ & E15 & $0.97 \mathrm{c}$ & E24 & $1.01 \mathrm{c}$ \\
\hline E7 & $1.03 \mathrm{~b}$ & E16 & $1.00 \mathrm{a}$ & E25 & $1.08 \mathrm{a}$ \\
\hline E8 & $1.00 \mathrm{a}$ & E17 & $0.99 \mathrm{~d}$ & E26 & $1.03 \mathrm{~b}$ \\
\hline E9 & $1.00 \mathrm{a}$ & E18 & $0.97 \mathrm{c}$ & E27 & $1.01 \mathrm{c}$ \\
\hline L.S.D. & $1 \mathrm{E}-9$ & L.S.D. & 0.0066 & L.S.D. & 0.0198 \\
\hline
\end{tabular}

Table 3 demonstrates the density of each emulsion in $\mathrm{g} / \mathrm{ml}$. Densities of all the emulsions were ranged from 0.96 $\mathrm{g} / \mathrm{ml}$ to $1.03 \mathrm{~g} / \mathrm{ml}$. It was found that in all emulsions, the density of solution decreased as the oil concentration increased. The results are similar to the findings of Homayoonfal et al., (2014) who optimized density, surface tension 
characterization of walnut oil nano-emulsion. They revealed that, density of solution decreased as the oil concentration increased.

Moreover it was found from the above table, as concentration of guar gum increases, thickness and density of solution increases. These results are in agreement with the statement given by Lindner et al., (2017) who told that when the thickness increases, the density of the solution also increases. On the other hand, from the previous trails of the present research it was found that emulsions containing more that $0.75 \%$ guar gum, leads to mould growth at ambient storage conditions. Therefore the low density emulsions with low thickness viz.E2 $(0.25 \%$ guar gum $+0.5 \%$ garlic essential oil $)$, E11 $(0.25 \%$ guar gum $+2 \%$ basil essential oil $)$ and E19 $(0.25 \%$ guar gum $+0.2 \% \alpha$-tocopherol $)$ showed better results.

\section{Antioxidant Activity}

DPPH Radical Scavenging Activity (\%)

Table 4: Antioxidant Activity of Emulsions with DPPH Assay

\begin{tabular}{|c|c|c|c|c|c|}
\hline \multicolumn{7}{|c|}{ Antioxidant Activity of Emulsions } \\
\hline Emulsion & \% inhibition of DPPH & Emulsion & \% inhibition of DPPH & Emulsion & \% inhibition of DPPH \\
\hline E1 & $94.74 \mathrm{a}$ & E10 & $90.25 \mathrm{a}$ & E19 & $89.69 \mathrm{a}$ \\
\hline E2 & $91.38 \mathrm{~b}$ & E11 & $85.28 \mathrm{~d}$ & E20 & $89.65 \mathrm{a}$ \\
\hline E3 & $86.36 \mathrm{~d}$ & E12 & $85.24 \mathrm{~d}$ & E21 & $89.53 \mathrm{a}$ \\
\hline E4 & $82.83 \mathrm{f}$ & E13 & $84.15 \mathrm{e}$ & E22 & $87.36 \mathrm{~b}$ \\
\hline E5 & $85.80 \mathrm{e}$ & E14 & $83.71 \mathrm{f}$ & E23 & $85.80 \mathrm{~b}$ \\
\hline E6 & $86.32 \mathrm{~d}$ & E15 & $86.20 \mathrm{c}$ & E24 & $82.83 \mathrm{c}$ \\
\hline E7 & $86.48 \mathrm{~d}$ & E16 & $86.68 \mathrm{~b}$ & E25 & $80.79 \mathrm{~d}$ \\
\hline E8 & $86.32 \mathrm{~d}$ & E17 & $86.28 \mathrm{c}$ & E26 & $79.19 \mathrm{~d}$ \\
\hline E9 & $88.65 \mathrm{c}$ & E18 & $86.24 \mathrm{c}$ & E27 & $80.94 \mathrm{~d}$ \\
\hline L.S.D. & 0.4058 & L.S.D. & 0.3606 & L.S.D. & 1.8156 \\
\hline
\end{tabular}

Table 4 showed \% inhibition of DPPH at the level of 94.74\% (GGOE), 90.25\% (GBOE) and $89.69 \%$ (GATE) by the emulsions. It can be said that garlic oil emulsion possess highest antioxidant activity which was $94.74 \%$ (E1: $0.25 \%$ guar gum $+0.125 \%$ garlic essential oil). Preliminary studies on the garlic essential oil mentioned its higher antioxidant activity. Shang et al., (2019) revealed that garlic exhibited stronger antioxidant activity evaluated by 1,1-diphenyl-2picrilhydrazyl (DPPH) radical scavenging assay, 2,2'-Azino-bis(3-ethyl-benzothiazoline-6-sulfonic acid) (ABTS) radical scavenging assay, and ferric ion reducing antioxidant power (FRAP) assay. Also, Lawrence et al., (2011) imparted from their study as garlic essential oil is effective in scavenging free radical and has the potential to be powerful antioxidant. Additionally, Ariviani et al., (2019) concluded as the incorporation of chitosan-garlic EO into beef meatballs edible coatings provide an alternative antioxidant-based functional food development, especially as the radical scavenger. 
Antioxidant Activity of Emulsions with ABTS Assay

Table 5: ABTS Radical Scavenging Activity (\%)

\begin{tabular}{|c|c|c|c|c|c|}
\hline \multicolumn{7}{|c|}{ Antioxidant Activity of Emulsions } \\
\hline GGOE & \% inhibition of ABTS & GBOE & \% inhibition of ABTS & GATE & \% inhibition of ABTS \\
\hline E1 & $14.41 \mathrm{c}$ & E10 & $18.12 \mathrm{~d}$ & E19 & $9.34 \mathrm{f}$ \\
\hline E2 & $21.45 \mathrm{c}$ & E11 & $16.66 \mathrm{e}$ & E20 & $19.53 \mathrm{bc}$ \\
\hline E3 & $17.32 \mathrm{c}$ & E12 & $15.82 \mathrm{f}$ & E21 & $17.46 \mathrm{cde}$ \\
\hline E4 & $27.93 \mathrm{bc}$ & E13 & $20.28 \mathrm{c}$ & E22 & $13.17 \mathrm{ef}$ \\
\hline E5 & $39.81 \mathrm{~b}$ & E14 & $23.61 \mathrm{a}$ & E23 & $17.04 \mathrm{cde}$ \\
\hline E6 & $19.48 \mathrm{c}$ & E15 & $17.98 \mathrm{~d}$ & E24 & $31.92 \mathrm{a}$ \\
\hline E7 & $87.04 \mathrm{a}$ & E16 & $21.27 \mathrm{~b}$ & E25 & $22.20 \mathrm{~b}$ \\
\hline E8 & $96.80 \mathrm{a}$ & E17 & $14.36 \mathrm{~g}$ & E26 & $18.87 \mathrm{bcd}$ \\
\hline E9 & $95.25 \mathrm{a}$ & E18 & $13.28 \mathrm{~h}$ & E27 & $14.27 \mathrm{de}$ \\
\hline L.S.D. & 13.773 & L.S.D. & 0.3941 & L.S.D. & 4.6357 \\
\hline
\end{tabular}

Table 5 represents the ABTS radical scavenging activity (\%) measured in terms of \% inhibition of ABTS. It was ranged from 14.41 to $96.80 \%$ by GGOE, from 13.28 to23.61\% and from 9.34 to31.92 \% by GATE. The results demonstrate as \% inhibition of ABTS was highest in GGOE (E8:0.75\% guar gum + 0.5\% garlic essential oil) which was $96.80 \%$. The statement can be justified by the findings of researchers given for the results of DPPH assay which showed maximum antioxidant activity by GGOE.

\section{Antioxidant Activity of Emulsions with FRAP Assay}

Table 6: Antioxidant Activity of Emulsions with FRAP Assay

\begin{tabular}{|c|c|c|c|c|c|}
\hline \multicolumn{7}{|c|}{ Antioxidant Activity of Emulsions } \\
\hline GGOE & $\boldsymbol{\mu} \mathbf{g} / \mathbf{m l}$ & $\mathbf{G B O E}$ & $\boldsymbol{\mu} \mathbf{g} / \mathbf{m l}$ & $\mathbf{G A T E}$ & $\boldsymbol{\mu} \mathbf{g} / \mathbf{m l}$ \\
\hline E1 & $42.05 \mathrm{~h}$ & E10 & $45.84 \mathrm{c}$ & E19 & $40.03 \mathrm{e}$ \\
\hline E2 & $43.57 \mathrm{~g}$ & E11 & $42.96 \mathrm{e}$ & E20 & $41.23 \mathrm{~d}$ \\
\hline E3 & $44.48 \mathrm{e}$ & E12 & $53.32 \mathrm{a}$ & E21 & $41.78 \mathrm{~d}$ \\
\hline E4 & $43.87 \mathrm{f}$ & E13 & $42.20 \mathrm{f}$ & E22 & $42.65 \mathrm{c}$ \\
\hline E5 & $45.64 \mathrm{~d}$ & E14 & $43.22 \mathrm{~d}$ & E23 & $42.32 \mathrm{c}$ \\
\hline E6 & $51.70 \mathrm{a}$ & E15 & $53.42 \mathrm{a}$ & E24 & $53.46 \mathrm{a}$ \\
\hline E7 & $48.37 \mathrm{c}$ & E16 & $43.42 \mathrm{~d}$ & E25 & $53.34 \mathrm{~b}$ \\
\hline E8 & $49.02 \mathrm{~b}$ & E17 & $43.27 \mathrm{~d}$ & E26 & $53.23 \mathrm{~b}$ \\
\hline E9 & $49.02 \mathrm{~b}$ & E18 & $49.73 \mathrm{~b}$ & E27 & $53.54 \mathrm{a}$ \\
\hline L.S.D. & 0.2125 & L.S.D. & 0.2409 & L.S.D. & 0.2056 \\
\hline
\end{tabular}

The findings of FRAP assay (Table 6) showed the antioxidant activity of GGOE ranged from 42.05 to $51.70 \mu \mathrm{Mol}$ TE/ml for GGOE, from 42.20 to $53.42 \mu \mathrm{mol} \mathrm{TE} / \mathrm{ml}$ for GBOE and from 40.03 to $53.54 \mu \mathrm{mol}$ TE/ml for GATE. The highest antioxidant activity showed by E27 (0.75\% guar gum $+0.6 \% \alpha$-tocopherol) at the level of $53.54 \mu \mathrm{mol} \mathrm{TE} / \mathrm{ml} \mathrm{in}$ GATE. It may be due to radical scavenging nature of alpha tocopherol (Sachdeva et al., 2014). 


\section{Antioxidant Activity of Emulsions with CUPRAC Assay}

Table 7: Antioxidant Activity of Emulsions with CUPRAC Assay

\begin{tabular}{|c|c|c|c|c|c|}
\hline \multicolumn{6}{|c|}{ Antioxidant Activity of Emulsions } \\
\hline GGOE & $\begin{array}{c}\text { mMol/ml_trolox } \\
\text { equivalent }\end{array}$ & GBOE & $\begin{array}{c}\text { mMol/ml_trolox } \\
\text { equivalent }\end{array}$ & GATE & $\begin{array}{c}\text { mMol/ml_trolox } \\
\text { equivalent }\end{array}$ \\
\hline E1 & $2461.88 \mathrm{c}$ & E10 & $2821.69 \mathrm{bc}$ & E19 & $2531.08 \mathrm{~b}$ \\
\hline E2 & $2493.44 \mathrm{c}$ & E11 & $2392.44 \mathrm{e}$ & E20 & $2503.34 b$ \\
\hline E3 & $2550.25 \mathrm{~b}$ & E12 & $2897.44 \mathrm{ab}$ & E21 & $2503.21 \mathrm{~b}$ \\
\hline E4 & $2638.63 a$ & E13 & $2947.94 a$ & E22 & $2615.45 a$ \\
\hline E5 & $2651.25 \mathrm{a}$ & E14 & $2607.07 \mathrm{~d}$ & E23 & $2631.67 \mathrm{a}$ \\
\hline E6 & $2259.87 \mathrm{e}$ & E15 & $2613.38 \mathrm{~d}$ & E24 & $2657.21 \mathrm{a}$ \\
\hline E7 & $2108.37 \mathrm{f}$ & E16 & $2695.44 d$ & $\mathrm{E} 25$ & $2038.47 \mathrm{~d}$ \\
\hline E8 & $2259.87 \mathrm{e}$ & E17 & $2872.19 \mathrm{abc}$ & E26 & $2026.76 \mathrm{~d}$ \\
\hline E9 & $2354.56 \mathrm{~d}$ & E18 & $2790.12 c$ & E27 & $2323.34 c$ \\
\hline L.S.D. & 46.366 & L.S.D. & 42.517 & L.S.D. & 42.356 \\
\hline
\end{tabular}

In CUPRAC assay a similar trend was observed (Table 7); value for antioxidant activity varied from 2108.37 to2651.25mMol TE/ml in GGOE, from 2392.44 to 2947.94 mMol TE/ml in GBOE and from 2026.76 to2657.21 $\mathrm{mMol}$ $\mathrm{TE} / \mathrm{ml}$ in GATE. The highest antioxidant activity $(2657.31 \mathrm{mMol} \mathrm{TE} / \mathrm{ml})$ showed by emulsion containing alpha tocopherol i.e. E24 (0.5\% guar gum $+0.6 \% \alpha$-tocopherol). Overall values of in the CUPRAC assay were significantly (p < 0.0001) higher than FRAP values. High antioxidant activity in CUPRAC may be attributed due to the combined effect of flavonoids such as flavanoids like kaempferol, myricetin guar gum and the phenolic compounds such as $\beta$-resorcylic acid, followed by pyrogallol, gallic acid, rutin, protocatechuic acid, as well as quercetin present in garlic essential oil (Shang et al.,2019). The antioxidant potency of flavonoids is roughly proportional to the total number of -OH groups and is positively affected by the presence of an o-dihydroxy moiety in the B-ring (Apak et al., 2008).

\section{CONCLUSIONS}

The emulsions containing $0.25 \%$ guar gum and $0.125 \%$ garlic oil has shown the least value of surface tension among all emulsions while emulsion containing $0.25 \%$ guar gum and $0.5 \%$ garlic oil showed the lowest density and found better for further study. DPPH and ABTS assays showed maximum antioxidant activities possessed by emulsion containing $0.25 \%$ guar gum and $0.125 \%$ garlic oil and emulsion containing $0.75 \%$ guar gum $+0.5 \%$ garlic essential oil respectively. FRAP and CUPRAC assays showed maximum antioxidant activity by emulsion formulated with $0.75 \%$ guar gum $+0.6 \% \alpha-$ tocopherol and emulsion made with $0.5 \%$ guar gum $+0.6 \% \alpha$-tocopherol respectively. The findings reveal that the emulsion of garlic oil and guar gum had obtained the best outcomes followed by the emulsion of $\alpha$-tocopherol has proved to be effective physicochemical attributed coatings.

\section{REFERENCES}

1. Apak, R., Güçlü, K., Özyürek, M., \&Çelik, S. E. (2007). Mechanism of antioxidant capacity assays and the CUPRAC (cupric ion reducing antioxidant capacity) assay. MicrochimicaActa, 160(4), 413-419.

2. Apak, R., Güçlü, K., Özyürek, M., Bektas, oğlu, B., \&Bener, M. (2008). Cupric Ion Reducing Antioxidant Capacity Assay for Food Antioxidants: Vitamins, Polyphenolics, and Flavonoids in Food Extracts. Advanced Protocols in Oxidative Stress I, 163193

3. Ariviani, Setya \& Kusumawati, M \& Atmaka, W. (2019).Chitosan-garlic essential oil incorporation on beef meatball edible coatings as antioxidant-based functional food. IOP Conference Series: Materials Science and Engineering. 633. 012032. 
4. Choi, W., Park, H., Anh, D., Lee, J., Lee, C., 2002.Wettability of chitosan coating solution on "Fuji” apple skin. J. Food. Sci. $66,2668-2672$

5. I. F. F Benzie.and J. J. Strain, "The ferric reducing ability of plasma (FRAP) as a measure of 'Antioxidant Power": The FRAP Assay, Analytical Biochemistry, Vol. 239, pp. 70-76, 1996.

6. Kanna, Rajesh \& Sharon, David \& Albert, Arun. (2017). Determining Changes in Interfacial Tension of Crude Oil using Alkalis. International Refereed Journal of Engineering and Science 6.1-4.

7. KJ Staff 2018.Reducing Post harvest Losses in fruits and vegetables. Krishijagaran.com https://krishijagran.com/news/reducing-post-harvest-losses-in-fv/

8. Lawrence, Reena \& Lawrence, Kapil. (2011). Antioxidant activity of garlic essential oil (Allium Sativum) grown in north Indian plains. Asian Pacific Journal of Tropical Biomedicine. 1. S51-S54.

9. Lindner, M., \& Schmid, M. (2017). Thickness Measurement Methods for Physical Vapor Deposited Aluminum Coatings in Packaging Applications: A Review. Coatings, 7(1), 9.

10. Mina Homayoonfal ,Faramarz Khodaiyan \& Seyed Mohammad Mousavi (2014) Walnut Oil Nanoemulsion: Optimization of the Emulsion Capacity, Cloudiness, Density, and Surface Tension, Journal of Dispersion Science and Technology, 35:5, 725733

11. Moncayo, D., Buitrago, G., Algecira, N., The surface properties of biopolymer-coated fruit: a review., Ingeniería e Investigación, Vol. 33, No. 3, December 2013, pp. 11 - 16.

12. Naik, G. Mohan, R F Sutar, and R. Jagan Mohan."Impact of Storage Temperature (7 C) and Post-Harvest Pre-Treatments on Quality Characteristics and Storage Life of Tomato (Lycopersiconesculentum) Fruits. "International Journal of Agricultural Science and Research (IJASR) 7. 4, Aug 2017, 23-30

13. Okoh, S.O.; Asekun, O.T.; Familoni, O.B.; Afolayan, A.J. Composition and antioxidant activities of leaf and root volatile oils of Moridalucida. J. Nat. Prod. Commun. 2011, 6, 1537-1541.

14. Othayoth, Rajath., Sravya. Kalivarapu, and Mahendran. Botlagunta."Nanophytomedicine and drug formulations." Int J NanotechnolAppl 4 (2014): 1-8.

15. Ribeiro, C., Vicente, A. A., Teixeira, J. A., \& Miranda, C. (2007).Optimization of edible coating composition to retard strawberry fruit senescence. Postharvest Biology and Technology, 44(1), 63-70.

16. Sachdeva M., Karan M., Singh T., Dhingra S. Oxidants and antioxidants in complementary and alternative medicine: A review. Spatula DD. 2014;4(1):1-16.

17. Samrat Sharma. 2019. India wastes up to $16 \%$ of its agricultural produce; fruits, vegetables squandered the most. Financial Express https://www.financialexpress.com/economy/india-wastes-up-to-16-of-its-agricultural-produce-fruits-vegetablessquandered-the-most/1661671/

18. Shang, Cao, Xu, Gan, Tang, Corke, Li. (2019). Bioactive Compounds and Biological Functions of Garlic (Allium sativum L. ).Foods, 8(7), 246.

19. Surendhiran, M., et al. "Nano Emulsion Seed Invigouration for Improved Germination and Seedling Vigour in Maize. "International Journal of Agricultural Science and Research (IJASR) 9. 3, Jun 2019, 333-340

20. Tamilselvan, T., and S. C. Prasanna. "Review on the Effect of Nanofiller Addition on the Technical Properties of Polymers." International Journal of Mechanical and Production Engineering Research and Development (IJMPERD) ISSN (P) (2018): 2249-6890.

21. Witayapan, N.; Sombat, C.; Siriporn, O. Antioxidant and antimicrobial activities of Hyptissuaveolens essential oil. Sci. Pharm. 2007, 75, 35-46. 